\title{
PENERAPAN KONSEP SMART CITY PADA KONTEKS KABUPATEN (KONSEP SMART CITY PADA KABUPATEN KULON PROGO)
}

\author{
Samuel Umbu Nday ${ }^{1}$ Achmad Djunaedi ${ }^{2}$ \\ (Yogyakarta, Indonesia) \\ Universitas Gadjah Mada.Indonesia \\ e-mail: ${ }^{1}$ samuel.nday10@mail.ugm.ac.id, 2adjun@ugm.ac.id.
}

\begin{abstract}
The Application of smart cities to regency area has not been widely implemented or is a new planning application. Concept that implemented to region of indonesia will give different result and effect specifically to regency area that have different characteristic from another region. Various change that caused from the start of application in 2018 until present brought impact to society, regional and government. Case study of the application of smart city concept is process will look directly at practice of smart city development with execution of the programs. The used method in the research is interview, observation, and data collection. The result will relate to the stage and process of growth, influence of factor, and the finding of changes that important in the development or will relates to progress of direction and focus of implementation throughout the practice of smart city programs. Factors that important cannot be separated from the growth of smart city development. Various change will be happened to Kulon Progo Regency as one of the regions that encourages application of smart city to brought benefit widely for government and society. The representation of the result is findings of revelation to the goal and the existing of development.
\end{abstract}

Keywords: Smart city, Regency, Region, Kulon Progo.

\begin{abstract}
ABSTRAK
Penerapan smart city di wilayah Kabupaten belum banyak diterapkan atau merupakan sebuah penerapan perencanaan yang masih baru. Konsep yang diterapkan di wilayah Indonesia akan memberikan hasil dan dampak yang berbeda. Khusus bagi wilayah Kabupaten yang mempunyai ciri atau karakterisitik yang berbeda dari wilayah lainnya akan menimbulkan hasil dan dampak secara spesifik pada area kabupaten yang mempunyai perbedaan karakteristik dari wilayah lainnya. Berbagai perubahan yang ditimbulkan sejak awal penerapan di tahun 2018 sampai sekarang membawa dampak tersendiri bagi masyarakat, wilayah dan pemerintah. Studi kasus pada penerapan konsep smart city di Kabupaten Kulon Progo merupakan proses yang akan melihat secara langsung praktik pengembangan smart city dan pelaksanaan program-programnya. Metode yang digunakan adalah wawancara, observasi dan pengumpulan data. Hasil penelitian berhubungan terhadap tahapan dan perkembangan, faktor berpengaruh serta temuan perubahan yang bersifat penting dalam pengembangan (devekopment) atau berhubungan dengan progres terhadap arah dan fokus penerapan selama program smart city dijalankan di wilayah Kabupaten. Faktor-faktor yang berpengaruh penting tidak terlepas dari perkembangan pengembangan smart city. Berbagai perubahan akan terjadi pada Kabupaten Kulon Progo sebagai salah satu wilayah yang mendorong adanya penerapan smart city sehingga bermanfaat luas bagi pemerintah dan masyarakat. Gambaran hasil merupakan temuan yang relevan terhadap tujuan dan pengembangan yang telah ada.
\end{abstract}

Kata kunci: Smart city, Kabupaten, Wilayah, Kulon Progo. 


\section{( \\ JURNAL REKSABUMI}

JournalHomepage: http://jurnal.ut.ac.id/reksabumi
P-ISSN: 0000-0000 dan E-ISSN: 0000-0000

Volume 1 Nomor 1, Januari 2022, 01-22

https://doi.org/10.33830/Reksabumi.v1i1.2159.2022

\section{PENDAHULUAN}

Praktik dan teori yang berkembang terkait smart city lebih banyak di terapkan di Kotakota yang tersebar di seluruh dunia. Indonesia sebagai salah satu yang menyelenggarakannya melalui program 100 smart city pada kota dan kabupaten perlu mengadaptasikan proses perencanaannya secara khusus agar jalannya penerapan lebih tepat berhubungan dengan masing-masing wilayah. Penerapan smart city pada wilayah Kabupaten atau regency juga masih menjadi bagian baru dalam perencanaan, sehingga masih perlu dikembangkan lagi seiring proses pengembangan yang sedang dijalankan. Kabupaten Kulon Progo melalui konsep perencanaan yang dilakukan secara inovatif dan produktif perlu menghubungkan prioritas pembangunan di daerah terhadap pelaksanaannya. Pengembangan program diarahkan secara khusus dalam mengangkat potensi daerah yang dapat membawa keuntungan dan berkembang secara berlanjut (Lord and Tewdwr-Jones. 2015). Kewilayahan merupakan wilayah geografis yang terbentuk dari pusat-pusat aktivitas secara spasial yang saling berinteraksi. Faktor-faktor dalam kewilayahan memberikan pengaruh dalam proses pengembangan smart city.sehingga perlu untuk melihat secara mendalam dan lebih jauh dalam melihat secara langsung hubungannya. Kabupaten dengan wilayahnya yang luas memiliki aktivitas dan fungsispasial yang beragam sehingga sudut pandang kewilayahan akan melihat pengaruh secarakhusus penerapan smart city di Kabupaten. Melihat lebih jauh, terdapat perkembangan wilayah dan masyarakat yang menjadi perhatian selain program-program yang diterapkan oleh pemerintah agar jalannya proses pengembangan bermanfaat secara tepat. Dampak dan perubahan terhadap keduanya menjadi perkembangan yang perlu dilihat secara bertahap dan mendalam.

Selain, itu terdapat berbagai peran dalam mendorong perkembangan smart city. Seluruh stakeholder bekerja sama dan saling berkolaborasi melalui kapasitas yang dimiliki dan melalui dukungan kebijakan serta peran pemerintah secara langsung bermanfaat dalam memberikan arahan dan mencari solusi yang tepat bagi dampak positif yang dapat berlanjut di Kabupaten.Giffinger, et al (2007) dan Djunaedi. A., et al (2017). Dalam Konsep smart city terdapat 6 dimensi yang dikembangkan agar dapat berkontribusi dalam membangun Kabupaten Kulon Progo. Arah pengembangannya secara menyeluruh dalam menyediakan pola sistem dan jaringan untuk mendukung perkembangan masyarakat, wilayah dan pemerintah. Serta memberikan manfaat secara internal maupun eksternal berkaitan dengan Kabupaten. Pengembangannya sendiri lebih pada infrastruktur dan pelayanan dalam memudahkan masyarakat maupun pihak yang mengelola secara langsung. Perkembangannya telah memberikan perubahan pada tata kelola dan proses kerja

pelayanan serta memberikan manfaat secara luas melalui pengembangan wilayah Kabupaten. Oleh karena itu, dalam penelitian ini bertujuan melihat proses pengembangan konsep smart city yang mengatasi berbagai permasalahan dan melihat proses tahapan yang berpengaruh dalam memberikan perubahan dan dampak positif bagi arah perkembangan secara berlanjut. Berbagai peran dan pelaksanaannya dapat terlihat lebih jauh melalui temuan faktor yang menjadi poin penting dan memiliki hubungan terhadap tahapan dan perkembangan penerapan konsep smart city pada konteks kabupaten. Proses penelitian secara kualitatif melalui metode studi kasus memberikan pemahaman secara menyeluruh terhadap arah pengembangan di wilayah Kabupaten. Sehingga dapat menjadi gambaran penerapan konsep smart city yang mendalam. Kontribusi dalam penelitian yang diberikan relevan terhadap pengembangan smart city yang sedang dijalankan. Secara 
keseluruhan, dapat menjadi sumber pembelajaran bagi tahapan pengembangan yang baru khususnya di Kabupaten.

\section{METODE PENELITIAN}

Metode yang digunakan adalah menghubungkan teori terhadap pengembangan konsep smart city dalam penerapannya pada konteks Kabupaten Kulon Progo. Penelitian menggunakan metode penelitian kualitatif. Dalam prosesnya melakukan wawancara, observasi dan pengumpulan data. Penelitian dilakukan menggunakan studi kasus terhadap agar penerapannya dapat dilihat secara langsung berkaitan terhadap peran pemerintah, para stakeholder, masyarakat, dan pihak-pihak yang memiliki hubungan selama jalannya proses pengembangan.

\section{Gambar 1. Metode Analisa Data}

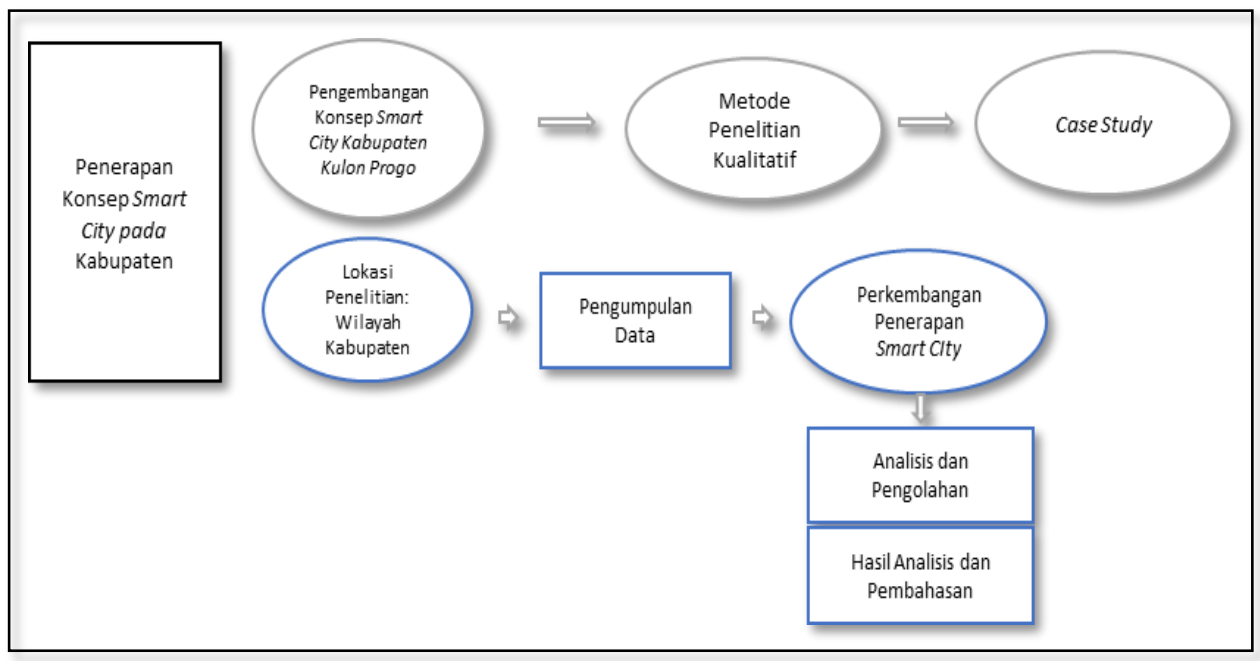

Sumber : Analisis Penulis. 2021.

Metode penelitian kualitatif menggunakan studi kasus atau case study dalam melihat penerapan smart city.di Kabupaten Kulon Progo. Proses wawancara menggunakan openended interview dengan mewawancarai narasumber secara langsung, observasi dan pengamatan langsung serta pengumpulan data dilakukan sehingga lebih relevan terhadap kondisi dan situasinya. Analisis dan pengolahan data dilakukan secara proses kualitatif di dalam mengkaji data secara detail untuk mempertimbangkan hubungannya terhadap fakta lapangan. Setelah itu, terdapat hubungan teori dalam penelitian penerapan konsep smart city pada konteks Kabupaten yang membantu dalam memperkuat proses studi kasus yang dilakukan. Penerapan smart city berhubungan terhadap Gerakan Menuju 100 smart city Nasional oleh KemenKominfo yang didalmnya memiliki 6 dimensi cerdas yaitu, smart governance, smart branding, smart economy, smart living, smart society, smart environment dengan pilarnya masing. Konsep smart city yang ada di Kabupaten Kulon Progo juga memliki hubungan langsung terhadap arahan oleh pihak pemerintah pusat selama proses pengembangan. 
Gambar 1.2. Peta Tata Ruang Kabupaten Kulon Progo

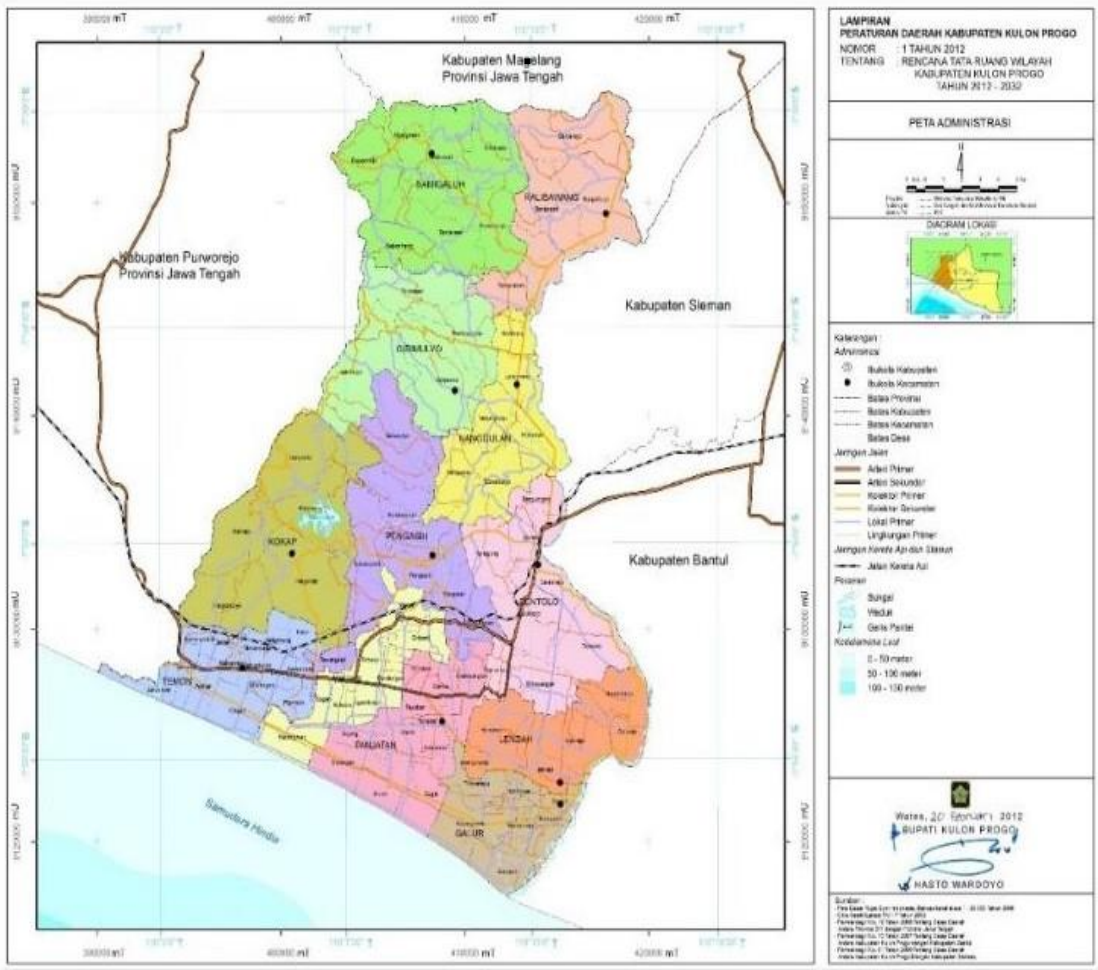

Sumber: Pemerintah Kabupaten Kulon Progo, 2012-2032

Lokasi Penelitian berada di Kabupaten Kulon Progo. Dalam melihat Perbedaan wilayah Kabupaten terhadap penerapan smart city di Kota atau wilayah lainnya yaitu, kabupaten memiliki ciri wilayah yang berbeda. Perbedaan yang nampak menonjol seperti luasnya wilayah kabupaten dan berbagai potensi lokal di dalamnya. Pengaruh wilayah Kabupaten dalam proses penelitian menempatkan wilayah sebagai salah satu fokus bagi penelitian sehingga penelusuran terkait kondisi wilayah diperlukan agar mengetahui cakupan pengembangan yang dilaksanakan. Wilayah Kabupaten memiliki beberapa poin penting berhubungan dengan masyarakat, budaya, ekonomi, potensi lokal dan pemerintah yang dipertimbangkan perkembangannya. Faktor lainnya yang dikembangkan datang dari keunggulan yang telah ada dan melekat atau memiliki hubungan dalam penerapan di Kabupaten Kulon Progo. 


\section{PEMBAHASAN}

Dalam Penelitian melihat tahapan dan perkembangan yang menjadi temuan dalam proses pengembangan (development). Perubahan-perubahan yang muncul dapat menjadi langkah penting yang dapat berkembang secara berlanjut. Berikut penjelasannya:

\section{Tabel 1.Tahapan dan Perkembangan dalam Pengembangan smart city Kabupaten Kulon Progo.}

\begin{tabular}{|c|c|c|}
\hline Tahun & Tahapan Pengembangan (Development) & Langkah Perubahan \\
\hline 2018 & $\begin{array}{l}\text { Penyediaan Infrastruktur smart city bagi desa dan } \\
\text { Kecamatan berbasis online } \\
\text { Pengembangan smart city Pelayanan dan Proses kerja } \\
\text { Pemerintahan (Governance) }\end{array}$ & $\begin{array}{l}\text { Kemudahan akses dan pelayanan } \\
\text { jaringan smart city. }\end{array}$ \\
\hline \multirow{4}{*}{2019} & $\begin{array}{l}\text { Penyediaan Infrastruktur secara berlanjut bagi desa dan } \\
\text { kecamatan berbasis online } \\
\text { Penyederhanaan proses pelayanan dan proses } \\
\text { birokrasi di dalamnya }\end{array}$ & $\begin{array}{l}\text { Menyediakan akses dan pelayan } \\
\text { smart city dalam menjangkau wilayah } \\
\text { yang luas. } \\
\text { Perubahan struktur dalam birokrasi } \\
\text { untuk mempercepat proses } \\
\text { pelayanan }\end{array}$ \\
\hline & $\begin{array}{l}\text { Pengembangan website, Single Website (JendelaKu) } \\
\text { media virtual. } \\
\text { OSS (Online Single Subminssion), Single Sign On, } \\
\text { Single Identity. Command centre. }\end{array}$ & $\begin{array}{l}\text { Pergeseran pola kerja dan pelayanan } \\
\text { masyarakat yang lebih cepat dan } \\
\text { akurat. }\end{array}$ \\
\hline & $\begin{array}{l}\text { Ruang Server, Cloud (Aplikasi Pemerintah Pusat), API } \\
\text { (Application Programming Interface). }\end{array}$ & $\begin{array}{l}\text { Pengintegrasian sistem dan aplikasi } \\
\text { serta peningkatan kinerja dalam smart } \\
\text { city. }\end{array}$ \\
\hline & $\begin{array}{l}\text { Pelatihan dan Literasi masyarakat dan SDM. } \\
\text { Peningkatan peran desa dan masyarakat } \\
\text { Penerapan Smart Infrastruktur yang secara lebih } \\
\text { spesifik mendukung jalannya pengembangan smart } \\
\text { city. }\end{array}$ & $\begin{array}{l}\text { Perbaikan kinerja pemerintah dan } \\
\text { dukungan bagi masyarakat dalam } \\
\text { memanfaatkan keunggulan smart city. }\end{array}$ \\
\hline 2020 & $\begin{array}{l}\text { Pengembangan platform virtual serta peningkatan } \\
\text { pelayanan (Pengembangan Program smart city dan } \\
\text { Pengaruh kondisi Pandemic Covid-19). }\end{array}$ & $\begin{array}{l}\text { Pengembangan sistem dan jaringan } \\
\text { secara virtual dalam mewadahi } \\
\text { proses kerja dalam lingkup } \\
\text { pemerintahan maupun pelayanan } \\
\text { masyarakat. }\end{array}$ \\
\hline 2021-n & $\begin{array}{l}\text { Pengembangan SPBE pada titik pengembangan smart } \\
\text { city di wilayah desa. }\end{array}$ & $\begin{array}{l}\text { Pengembangan wilayah desa dan } \\
\text { smart village. }\end{array}$ \\
\hline
\end{tabular}

Sumber : Analisa Penulis. 2021.

Pengembangan smart city dilakukan untuk menjangkau wilayah kabupaten yang memiliki 8 kecamatan dan 87 desa atau kalurahan dengan pengembangan jaringan fiber optic dan peningkatan bandwith. Secara lebih jauh pengembangannya bertahap dalam berhubungan terhadap perencanaan $100 \%$ desa dan kecamatan berbasis online. Keberadaan infrastrukturnya dikembangkan bagi lingkup pemerintah kabupaten, kecamatan dan desa. Sedangkan, bagi masyarakat di wilayah kabupaten terdapat pelayanan cerdas dan jaringan yang mendukung kemudahan akses. Selain itu, terdapat jaringan backbone kabupaten yang dikelola menggunakan media transmisi dan wireless yang bermanfaat bagi koneksi antar OPD. Dalam pelayanan pemerintah juga 
dikembangkan sistem Government Service Bus yang mendukung integrasi dan pelayanan data. Inovasi dan pengembangan dalam sistem melengkapi fungsi dan manfaat smart city.

\section{Gambar 3. Sistem Integrasi dalam Layanan aplikasi dan Data (GSB).}

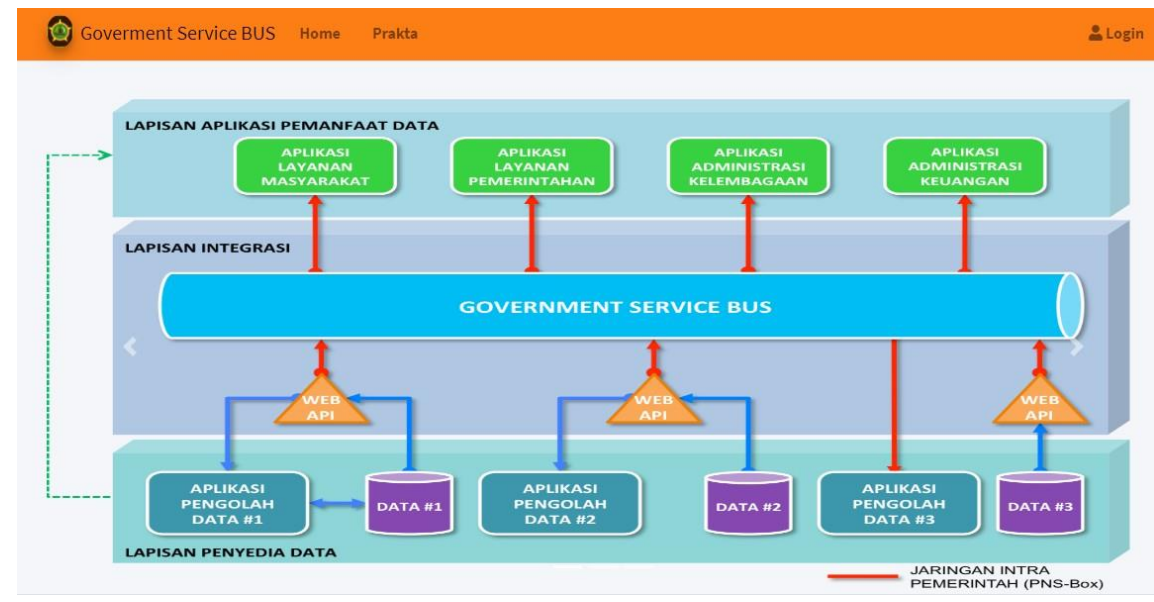

Sumber: Dinas Komunikasi dan Informatika Kulon Progo. 2021.

Tabel 2. Inovasi dan Pengembangan dalam sistem dan pelayanan di Kabupaten Kulon Progo.

\begin{tabular}{|c|c|c|}
\hline No. & Inovasi dan Pengembangan & Manfaat \\
\hline 1. & Single Identity dan Single Sign On & Akses dengan menggunakan single akun \\
\hline 2. & Single Website & $\begin{array}{l}\text { Pengembangan pelayanan multi-link dan akses bagi multi- } \\
\text { pelayanan }\end{array}$ \\
\hline 3. & OTS (Online Tracking System), & $\begin{array}{l}\text { Proses tracking pelayanan yang bisa dipantau oleh } \\
\text { masyarakat dan pemerintah. }\end{array}$ \\
\hline 4. & Ruang Server & $\begin{array}{l}\text { Penyimpanan dan pengelolaan data sertu dukungan bagi } \\
\text { kinerja proses }\end{array}$ \\
\hline 5. & Cloud & $\begin{array}{l}\text { Penyimpanan data dan proses kerja terintegrasi bersama } \\
\text { pemerintah pusat. }\end{array}$ \\
\hline 6. & $\begin{array}{l}\text { API (Application Programming } \\
\text { Interface) }\end{array}$ & $\begin{array}{l}\text { Pengintegrasian sistem dan pelayanan, pengelolaan data } \\
\text { dan manajemen data. }\end{array}$ \\
\hline 7. & smart city In Roaming, & $\begin{array}{l}\text { Pelayanan internet publik berkualitas (terstandardisasi } \\
\text { bagi pemerintah dan masyarakat). }\end{array}$ \\
\hline 8. & OSS (online single submission), & $\begin{array}{l}\text { Memperlancar dan mempercepat kinerja pemerintah dan } \\
\text { kerja operator sistem pelayanan untuk proses kerja yang } \\
\text { lebih cepat dan terkendali, serta pengintegrasian sistem } \\
\text { dan pelayanan }\end{array}$ \\
\hline 10. & $\begin{array}{l}\text { Geographic Information System } \\
\text { (GIS), }\end{array}$ & $\begin{array}{l}\text { Pengembangan pelayanan berbasis GIS yang akurat dan } \\
\text { mendukung pelayanan cerdas. }\end{array}$ \\
\hline 11. & Data Center & Pemrosesan, penyimpanan database dan telekomunikasi. \\
\hline 12. & $\begin{array}{l}\text { Teleconference dan Command } \\
\text { Center }\end{array}$ & $\begin{array}{l}\text { Koordinasi kinerja dan video conference pada lingkup } \\
\text { pemerintah daerah. }\end{array}$ \\
\hline
\end{tabular}

Sumber : Dinas Komunikasi dan Informatika Kulon Progo. 2021.

Temuan perubahan-perubahan dalam penerapan smart city di Kabupaten Kulon Progo: 
1. Transformasi dalam Infrastruktur dan Pola Pelayanan masyarakat.

2. Pergeseran Birokrasi.

3. Perubahan pola kerja dan pelayanan dalam smart city yang cepat dan akurat.

4. Pengembangan terhadap ciri khas wilayah Kabupaten Kulon Progo (smart agriculture dan pariwisata).

Melalui temuan dapat melihat progres dan tahapan penting yang memberikan manfaat bagi peningkatan kualitas pelayanan maupun masyarakat secara langsung. Program yang dijalankan telah melalui proses perencanaan, rekomendasi, spesifikasi yang sesuai dengan kebutuhan di wilayah Kabupaten Kulon Progo. Gambaran proses bagi Kabupaten Kulon Progo dalam menghadapi tantangan selama pengembangan smart city yaitu wilayah Kabupaten yang luas menyebabkan infrastruktur harus cukup masif dikembangkan dibarengi dengan pengembangan pelayanan yang sesuai atau cocok pada setiap bagian wilayahnya. Dengan adanya jaringan dan akses bagi internet menjadi pelayanan dasar yang dapat bertumbuh lebih baik sehingga dapat manfaatnya dapat dirasakan oleh seluruh masyarakat. Proses pengembangan berkaitan dengan pemerintah kabupaten pada struktur dan birokrasi. Pemerintahan di Kabupaten mempunyai pembagian wilayah administratif yang berbeda terhadap perkotaan yaitu terdapat, Pemerintah Daerah, Pemerintah Kota, Pemerintah Kecamatan dan Pemerintah Desa. Sehingga dalam proses pengembangannya membutuhkan kerja sama sesuai proses dan aturan kepemerintahan. Resistensi pada pola pelayanan pemerintah yang sudah lama membuat adanya penundaan dalam proses pelayanan. Reformasi birokrasi atau penyederhanaan birokrasi dalam pelayanan smart city sangat dibutuhkan untuk efisiensi dan efektivitas pelayanan.

Ciri khas Kabupaten Kulon Progo yang memiliki potensi pertanian, pariwisata serta potensi lokal lainnya membuka peluang bagi inovasi dalam memanfaatkan potensinya agar bisa membuka pasar lebih luas dan terjangkau, meningkatkan pendapatan dan mendatangkan keuntungan. Proses perkembangan teknologi yang lambat di beberapa wilayah Kabupaten mengakibatkan menurunnya manfaat pengembangan smart city. Sehingga, Pengembangan bagi peningkatan literasi masyarakat dan peran masyarakat dapat memberikan manfaat pembangunan yang berdampak positif. Program smart city bertujuan meningkatkan kualitas kinerja berbasis teknologi membutuhkan penyusunan program dalam mengembangkan pelayanan dan aplikasi segingga bermanfaat bagi efisiensi dan efektivitas proses pelayanan untuk pemerintah dan masyarakat. Penyediaan aplikasi yang terintegrasi dan layanan aplikasi secara virtual sangat membantu dalam mendukung proses kerja di dalamnya khususnya di wilayah kabupaten yang luas. Secara keseluruhan peran pemerintah terlihat mengambil peran utama serta berkontribusi besar dalam proses pembangunan dan perencanaan. Perannya berjalan terus-menerus ditengah hambatan dan keterbatasan yang dihadapi. Selanjutnya, Proses penelitian yang telah dijalankan terhadap pengembangan Konsep smart city pada Konteks Kabupaten menemukan faktor utama yang berpengaruh dalam pengembangannya di Kabupaten Kulon Progo yaitu, Pemerintah, Birokrasi. Pihak Swasta atau Pihak Ketiga, dan Masyarakat. Sebagai faktor kuat dalam proses pengembangan yang memiliki hubungan dan peran penting. Wilayah atau Region Kabupaten merupakan fokus pengembangan smart city yang memilki pengaruh dalam potensi dan karakteristik wilayahnya. Proses pengembangan yang dilakukan terhadap wilayah dapat berpengaruh secara langsung dan tidak langsung.

Pengumpulan data yang relevan telah menemukan tujuan (goals) dan perubahanperubahan sebagai progres atau proses penting yang juga berkaitan terhadap faktor-faktor 
utamanya. Tahapan selanjutnya berdasarkan proses penelitian yang telah melihat Penerapan konsep Perencanaan smart city dan melalui proses analisis maka menemukan faktor-faktor berpengaruh penting dalam pengembangannya di wilayah Kabupaten Kulon Progo. Sebagai Berikut:

1. Pemerintah.

Pemerintah sebagai pihak penyelenggara mendukung dan memilki peran utama dalam proses perencanaan dan pembangunan. Dalam proses penerapannya pemerintah berkolaborasi dengan berbagai pihak dalam mengarahkan pengembangan smart city. Selain itu pengembangan pelayanan dalam proses pemerintahan membantu mempercepat mekanisme yang bermanfaat bagi masyarakat dan pemerintah.

2. Birokrasi

Peran birokrasi dalam proses pelayanan mendukung jalannya kelancaran bagi berbagai pihak dan secara khusus bagi masyarakat.

3. Pihak Ketiga dan Pihak Swasta.

Pengembangan smart city tidak hanya dilakukan oleh pemerintah tetapi juga melalui kerja sama dan kolaborasi dalam mendukung dan memberikan manfaat secara optimal dan maksimal.

4. Masyarakat

Peran dan keterlibatan masyarakat yang bersama-sama dalam membangun wilayah atau daerah kabupaten selama pengembangan smart city. Kebutuhan masyarakat dan SDM juga menjadi pertimbangan utama baik yang dilakukan pihak pemerintah sebagai penyelenggara dan para stakeholder yang mendukung pengembangan smart city.

Tabel 3 Faktor-faktor penting yang berpengaruh dalam pengembangan smart city Kabupaten Kulon Progo.

\begin{tabular}{|c|c|c|c|}
\hline No. & $\begin{array}{c}\text { Faktor } \\
\text { berpengaruh } \\
\text { dalam } \\
\text { Penerapan Smart } \\
\text { city }\end{array}$ & Hubungan Situasi di Kabupaten Kulon Progo & $\begin{array}{c}\text { Gambaran Penerapan } \\
\text { (Goals) }\end{array}$ \\
\hline 1. & $\begin{array}{c}\text { Pemerintah atau } \\
\text { Government }\end{array}$ & $\begin{array}{l}\text { 1. } \begin{array}{l}\text { Dukungan bupati dalam memberikan } \\
\text { arahan secara terfokus bagi } \\
\text { pengembangan smart city }\end{array} \\
\text { 2. Pengembangan infrastruktur atau sarana } \\
\text { prasarana smart city pada desa dan } \\
\text { kecamatan. } \\
\text { 3. Pengembangan pelayanan Pemerintah, } \\
\text { Pelayanan bagi masyarakat dan } \\
\text { Pelayanan Publik (sarana dan prasarana). } \\
\text { 4. Kerja sama antar pemerintah dan pihak } \\
\text { swasta serta pihak ketiga. } \\
\text { 5. Pengembangan potensi lokal (pariwisata, } \\
\text { pertanian dan Hasil lokal). } \\
\text { 6. Pengembangan pelayanan terhadap } \\
\text { 7. Pualitas lingkungan. } \\
\text { Pengembangan berbasis budaya lokal. }\end{array}$ & 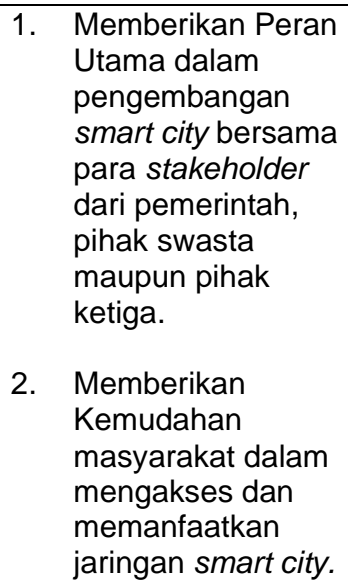 \\
\hline
\end{tabular}




\begin{tabular}{|c|c|c|c|c|}
\hline & & & $\begin{array}{l}\text { DPRD membantu dalam pengeluaran } \\
\text { kebijakan dan regulasi. Dalam } \\
\text { mengerahkan stakeholder dan mendukung } \\
\text { lancarnya pengembangan. }\end{array}$ & \\
\hline 2. & Birokrasi & & $\begin{array}{l}\text { Reformasi birokrasi dalam mempercepat } \\
\text { proses dan kemudahan pelayanan. } \\
\text { Peningkatan peran pemimpin dalam } \\
\text { sistem dan pelayanan. }\end{array}$ & $\begin{array}{l}\text { Memberikan langkah } \\
\text { yang mudah dan cepat } \\
\text { dibantu dengan sistem } \\
\text { dan pelayanan yang } \\
\text { cerdas. }\end{array}$ \\
\hline 3. & Masyarakat & $\begin{array}{l}11 . \\
12 . \\
13 . \\
14 . \\
15 . \\
16 . \\
17 .\end{array}$ & $\begin{array}{l}\text { Pengembangan program yang bermanfaat } \\
\text { bagi masyarakat secara luas untuk } \\
\text { mendapatkan pelayanan secara cepat. } \\
\text { Pengembangan potensi daerah yang } \\
\text { bermanfaat luas bagi masyarakat. } \\
\text { Bansos (Bantuan Sosial) } \\
\text { Peningkatan pendapatan (Income) dan } \\
\text { perekonomian masyarakat. } \\
\text { Literasi dan program pengembangan bagi } \\
\text { masyarakat \& SDM. } \\
\text { Peran dan keterlibatan masyarakat secara } \\
\text { langsung dalam mendukung pengembangan } \\
\text { smart city. } \\
\text { Pengembangan smart society : Dalam } \\
\text { mendukung pengembangan pada lapangan } \\
\text { kerja, pendidikan, keamanan bagi } \\
\text { masyarakat. }\end{array}$ & $\begin{array}{l}\text { Memberikan manfaat } \\
\text { luas seiring dalam } \\
\text { perekonomian, } \\
\text { masyarakat dan SDM } \\
\text { di wilayah Kabupaten. }\end{array}$ \\
\hline 4. & $\begin{array}{c}\text { Pihak Swasta dan } \\
\text { Pihak Ketiga }\end{array}$ & $\begin{array}{l}18 . \\
19 .\end{array}$ & $\begin{array}{l}\text { Kerja sama dalam pengembangan } \\
\text { Infrastruktur atau Sarana prasarana } \\
\text { Memberikan dukungan infrastruktur yang } \\
\text { bisa mendorong pengembangan smart city } \\
\text { secara luas di Kabupaten. }\end{array}$ & $\begin{array}{l}\text { Kolaborasi dan } \\
\text { mendukung } \\
\text { pengembangan } \\
\text { infrastruktur dan } \\
\text { jalannya program } \\
\text { smart city. }\end{array}$ \\
\hline
\end{tabular}

Sumber : Analisa Penulis. 2021.

\section{KESIMPULAN}

Penelitian dalam melakukan studi kasus terhadap penerapan smart city pada Konteks Kabupaten akan melihat perkembangan yang terjadi di kabupaten Kulon Progo. Pemerintah telah melakukan tahapan-tahapan penting yang berdampak kuat dan signifikan dalam memberikan manfaat yang luas. Penerapan pada konteks kabupaten tidak menjadi sebuah hambatan besar bagi pemerintah untuk terus mengembangkan smart city agar dapat menjangkau wilayah Kulon Progo secara luas.

Melalui faktor-faktor utama dalam pengembangan smart city di Kabupaten Kulon Progo dapat melihat bahwa dalam proses pengembangan pemerintah memiliki tantangan dalam penerapannya di wilayah Kabupaten. Pengaruh situasi dan kondisi yang relevan terhadap masyarakat dan wilayahnya menjadi pertimbangan khusus dalam melihat karakteristik di dalamnya. Selain itu, pihak yang terlibat dan perannya memberikan bagi pelaksanaannya.

Proses dalam perencanaan merupakan langkah penting yang bermanfaat dalam mendeteksi kebutuhan yang tepat dan cocok atau sesuai terhadap situasi dan kondisi pada Kabupaten. Pembangunan yang berjalan melibatkan kerja sama dan kolaborasi dengan para stakeholder dalam membangun smart city agar manfaat pengembangannya bisa berdampak secara berlanjut. Selanjutnya, proses pengembangan yang optimal dapat 
melalui partisipasi atau keterlibatan pihak dan masyarakat untuk dapat melakukan inovasi dan kegiatan dalam mendukung manfaat pengembangannya. Hasil penelitian secara keseluruhan dapat menjadi pembelajaran dalam bidang perencanaan khususnya dalam pengembangan terhadap wilayah Kabupaten.

\section{UCAPAN TERIMA KASIH}

Ucapan Terima Kasih kepada Universitas Gadjah Mada yang telah mendukung dalam pengadaan penelitian dan Pemerintah Kabupaten Kulon Progo yang telah membantu dan mendukung secara langsung bagi kelancaran proses penelitian.

\section{DAFTAR PUSTAKA}

Djunaedi, Achmad dan Tim Penyusun. 2018 ."Langkah-langkah menuju Smart city”. Kasus Kota Yogyakarta.

Djunaedi, Achmad dan Tim Penulis. 2018 ."Membangun Kota dan Kabupaten Cerdas sebuah panduan bagi Pemerintah Daerah." Gadjah Mada University Press.

Giffinger, R. Fertner, C. Kalazek K. Milanovic, N.P. 2007. "Smart Cities: Ranking of European Mid-Sized Cities.” Digital Agenda for Europe, no. October: 28.

Deakin, Mark. 2014. "Smart Cities (Governing, Modeling and analysing the transition)." Routledge.

Morandi. C, Rolando, A. Di Vita, S. 2016. "From smart city to Smart Region". Springer International Publishing.

Mahi, A. K. 2016. "Pengembangan Wilayah, Teori dan Aplikasi." Kencana.

Yunus, H. S. 2016. "Metodologi Penelitian Wilayah Kontemporer." Pustaka Pelajar.

Yin, R. K. 2002. "Case Study Research: design methods." Sage Publications.

Darono, Agung. 2017. "Implementasi Government Service Bus oleh Organisasi Pemerintahan di Indonesia: Perspektif Institutional Arrangement." Seminar Nasional Aplikasi Teknologi Informasi (SNATI).

Dameri, Renata Paola. 2013. "Searching for smart city Definition: A Comprehensive Proposal." International Journal of Computers \& Technology 11 (5): 2544-51.

Lord, Alex, and Mark Tewdwr-Jones. 2015. Regional Planning. International Encyclopedia of the Social \& Behavioral Sciences: Second Edition.

Treib, Oliver, Holger Bähr, and Gerda Falkner. 2007. "Modes of Governance: Towards a Conceptual Clarification." Journal of European Public Policy 14 (1): 1-20.

Grindle, Merilee S. 2007. "Good Enough Governance Revisited." Development Policy Review. 25 (5): 553-574

Pemerintah Kabupaten Kulon Progo. Buku II Master Plan smart city Kabupaten Kulon Progo Tahun 2018-2028. Tahun 2018.

Rencana Pengembangan smart city di Kabupaten Kulon Progo Tahun 2017-2022 